\title{
A STUDY OF FERROFLUID LUBRICATION BASED ROUGH SINE FILM SLIDER BEARING WITH ASSORTED POROUS STRUCTURE
}

\author{
Mohmmadraiyan M. Munshi ${ }^{a, *}$, Ashok R. Patel $^{b}$, Gunamani B. Deheri $^{c}$ \\ ${ }^{a}$ Gujarat Technological University, Alpha College of Engineering and Technology, Kalol, Gujarat, 382721, India \\ ${ }^{b}$ Gujarat Technological University, Vishwakarma Government Engineering College, Ahmedabad, Gujarat, 382424, \\ India \\ ${ }^{c}$ Sardar Patel University, Department of Mathematics, Vallabh Vidhyanagar, Gujarat, 388120, India \\ * corresponding author: raiyan.munshi@gmail.com
}

\begin{abstract}
This paper attempts to study a ferrofluid lubrication based rough sine film slider bearing with assorted porous structure using a numerical approach. The fluid flow of the system is regulated by the Neuringer-Rosensweig model. The impact of the transverse surface roughness of the system has been derived using the Christensen and Tonder model. The corresponding Reynolds' equation has been used to calculate the pressure distribution which, in turn, has been the key to formulate the load carrying capacity equation. A graphical representation is made to demonstrate the calculated value of the load carrying capacity which is a dimensionless unit. The numbers thus derived have been used to prove that ferrofluid lubrication aids the load carrying capacity. The study suggests that the positive impact created by magnetization in the case of negatively skewed roughness helps to partially nullify the negative impact of the transverse roughness. Further investigation implies that when the Kozeny-Carman's model is used, the overall performance is enhanced. The Kozeny-Carman's model is a form of an empirical equation used to calculate permeability that is dependent on various parameters like pore shape, turtuosity, specific surface area and porosity. The success of the model can be accredited to its simplicity and efficiency to describe measured permeability values. The obtained equation was used to predict the permeability of fibre mat systems and of vesicular rocks.
\end{abstract}

KEYWORDs: Porous structure, roughness, ferrofluid, load carrying capacity.

\section{INTRODUCTION}

The last decade has seen a considerable shift wherein many tribological researches have been dedicated to study surface roughness and the impact of hydrodynamic lubrication. This is because every solid surface carries some amount of surface roughness, the height of which is usually parallel to the mean separation between lubricated contacts. As many researchers have suggested, studying the surface roughness will help to improve the performance of a bearing system. Due to this reason, many researchers [1-3] studied the performance of various bearing systems using the stochastic concept of 46 .

Amongst the biggest inventions in the field is the use of ferrofluid as a bearing system lubricant. A number of authors [7-11] have worked to explain the performance and applications of ferrofluid when used in different types of bearing systems. These studies have suggested that ferrofluid impacts the bearing performance positively.

Many researchers have used different types of film geometries in order to study the effect of ferrofluid based squeeze film. Some of the researches conducted on this topic are listed, [12 studied exponential slider bearing, [13] worked on secant shaped slider bearing, [14 16] analysed inclined slider bearing, [17] stud- ied curved slider bearings, [18] examined parallel slider bearing, [19] evaluated on Rayleigh step bearing, [20] investigated parabolic slider bearing, 21] worked on hyperbolic slider bearing, 22] discussed sine film thrust bearing, 23] studied convex pad slider bearing and 24 examined infinitely long slider bearing. From all the articles above, it can clearly be seen that the characteristics of ferrofluid and its effect on load bearing capacity are positive.

The lubrication theory of porous bearings was first studied by [25]. Porous structures are usually described using two common parameters, which are porosity and permeability. Porosity is a measure of existing voids within a dense material structure. Permeability defines the ease with which fluids can flow through the material, in case of open cell porosity. Darcy's law is generally used to determine the porosity. Porous metallic materials have a lot of applications including vibration and sound absorption, light materials, heat transfer media, sandwich core for different panels, various membranes and during the last years as suitable biomaterial structures for the design of medical implants. Porous matrix decreases the load carrying capacity and increase the frictional force on the slider. The porous layer has a beneficial property of self-lubrication, making it an important area of 
study. [26] worked on studying the comparisons of porous structures and their impact on the load carrying capacity of a magnetic fluid based rough and short bearing. The studies have found that while magnetization has a positive impact on the bearing system's performance, transverse roughness impacts it negatively. However, in the case of Kozeny-Carman model, this negative impact is comparatively lower. In this model, the negative impact of porosity on the bearing performance can be neutralized with the negatively skewed roughness' positive impact. [27] worked on investigating the performance of a magnetic fluid based double layered rough porous slider bearing considering the combined porous structures. For a considerable range of combined porous structure, magnetization neutralizes the adverse effect of roughness. 28 studied Shliomis model-based magnetic squeeze film in rotating rough curved circular plates: making a contrast of two different porous structures. It was found out that by choosing a proper rotation ratio and appropriate curvature parameters, the negative impacts of transverse roughness on a bearing's load carrying capacity can be nullified by the positive impact of magnetization with a negatively skewed roughness. 29] studied squeeze film based on ferrofluid in curved porous circular plates with various porous structures. The studies showed that, with concave plates and porous structure given by Kozeny-Carman, there was a considerable increase in the load bearing capacity. Different forms of modification of Darcy's law have been studied in [30. 31] investigated a bearing system based on a hyperbolic slider. They experiment with porous structure as well as roughness in accordance with the impact of sinusoidal magnetic field. Furthermore, the load bearing capacity is enhanced due to the influence of magnetization and the slip parameter being within the limited boundary. Recently, 32 analysed inclined slider bearing. In this work, we can identify that they worked in detail with all aspects of surface roughness, porosity and magnetic field. Somehow, by surprise, the result was that the load bearing capacity differs and gives a very effective ability when the sinusoidal magnetic field is applied in the form which appears in the presented study.

None of the above-mentioned researchers worked on the impact of sine films in a slider bearing. In order to explore this filed, this paper studies ferrofluid lubrication based rough sine film slider bearing with assorted porous structure.

\section{ANALYSiS}

Figure 1 represents the geometry and configuration of the given bearing system. $U$ denotes the uniform velocity of the system in the direction $x$.

The thickness $\boldsymbol{h}$ is considered as

$$
\boldsymbol{h}=h+h_{s}
$$

where $h$ is taken as 22 :

$$
h=h_{0}+\left(h_{1}-h_{0}\right)\left[1-\sin \left(\frac{\pi x}{2 L}\right)\right]
$$

using the works of [4] . Also, the study uses $h_{s}$ using the probability density function

$$
f\left(h_{s}\right)=\left\{\begin{array}{l}
\frac{35}{32 c}\left(1-\frac{h_{s}^{2}}{c^{2}}\right)^{3}, \quad-c \leq h_{s} \leq c \\
0 \quad, \text { elsewhere }
\end{array}\right.
$$

$c$ being the maximum deviation from the mean film thickness. $\alpha, \sigma$ and $\varepsilon$ are considered by the relationships

$$
\alpha=E\left(h_{s}\right), \quad \sigma^{2}=E\left(h_{s}-\alpha\right)^{2}, \quad \varepsilon=E\left(h_{s}-\alpha\right)^{3}
$$

where $E(\bullet)$ denotes the expectancy operator given by

$$
E(\bullet)=\int_{-c}^{c}(\bullet) f\left(h_{s}\right) d h_{s}
$$

[9] formulated explaining the steady flow of a magnetic fluid. It was:

Equation of motion

$$
\rho(\bar{q} \cdot \nabla) \bar{q}=-\nabla p+\eta \nabla^{2} \bar{q}+\mu_{0}(\bar{M} \cdot \nabla) \bar{H}
$$

Equation of magnetization

$$
\bar{M}=\bar{\mu} \bar{H}
$$

Equation of continuity

$$
\nabla \cdot \bar{q}=0
$$

Maxwell equations

$$
\nabla \times \bar{H}=0
$$

and

$$
\nabla \cdot(\bar{H}+\bar{M})=0
$$

where $\rho, \bar{q}, \bar{M}, p$ and $\eta$ are fluid density, fluid velocity, magnetization vector, film pressure and fluid viscosity respectively.

Also,

$$
q=u i+v j+w k
$$

where $u, v, w$ are components of film fluid velocity in $x, y$ and $z$-directions respectively. Further, the magnetic field's magnitude is given by

$$
H^{2}=k x(L-x)
$$

where $k$ is a suitable constant and, assuming the external magnetic field to come up from a potential function, the inclination angle of the magnetic field $\phi=\phi(x, z)$ satisfies the equation [7]

$$
\cot \phi \frac{\partial \phi}{\partial x}+\frac{\partial \phi}{\partial z}=\frac{2 x-L}{2 x(L-x)}
$$

The governing equation of motion of the fluid flow in the film region 33 is

$$
\frac{\partial^{2} u}{\partial z^{2}}=\frac{1}{\eta} \frac{\partial}{\partial x}\left(p-\frac{1}{2} \mu_{0} \bar{\mu} H^{2}\right)
$$




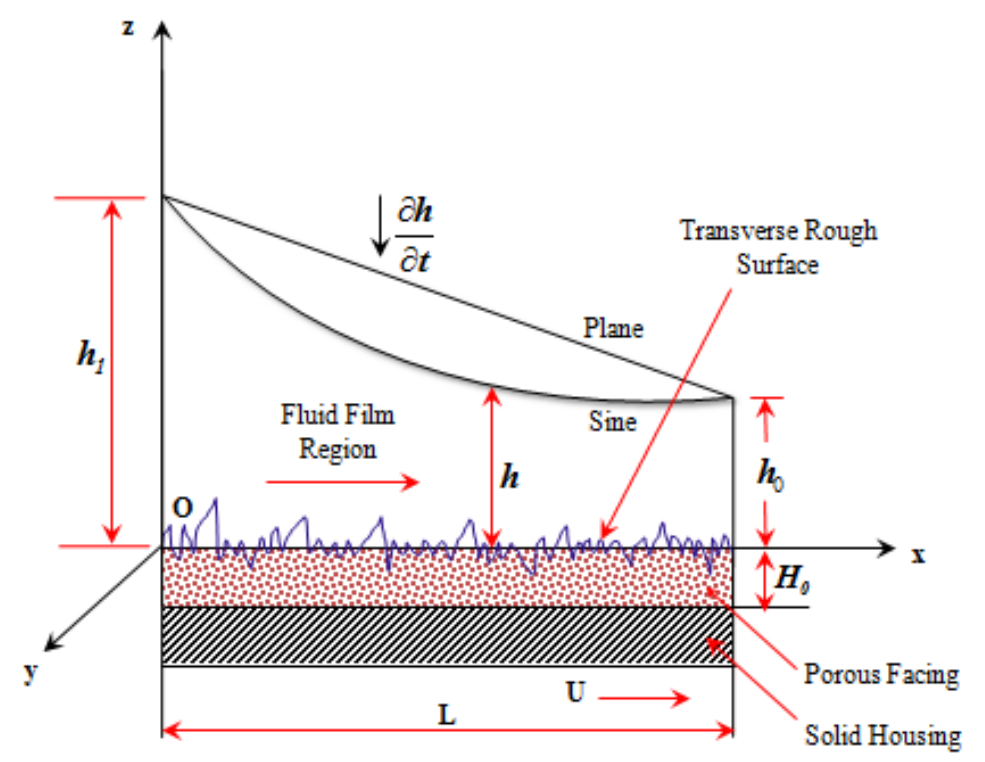

FIGURE 1. Configuration of a sine film porous slider bearing including squeeze action [22].

By solving equation 13 following the no slip boundary conditions:

$$
u=0 \text { at } z=h \text { and } u=U \text { at } z=0
$$

One can find

$$
u=\frac{1}{\eta}\left(\frac{z^{2}}{2}-\frac{h}{2} z\right) \frac{\partial p}{\partial x}+U\left(1-\frac{z}{h}\right)
$$

Integrating equation 14 over the film region, yields

$$
\int_{0}^{h} u d z=\frac{-h^{3}}{12 \eta} \frac{d p}{d x}+\frac{U h}{2}
$$

Using equation 15 in continuity equation

$$
\frac{\partial}{\partial x} \int_{0}^{h} u d z+w_{h}-w_{0}=0
$$

yields

$$
\frac{\partial}{\partial x}\left[\frac{-h^{3}}{12 \eta} \frac{d p}{d x}+\frac{U h}{2}\right]+w_{h}-w_{0}=0
$$

where

$$
w_{h}=-\dot{h_{0}} \quad \text { and } \quad w_{0}=0
$$

Equation (17) leads to:

$$
\frac{d}{d x}\left[\boldsymbol{h}^{3} \frac{d}{d x}\left(p-\frac{1}{2} \mu_{0} \bar{\mu} H^{2}\right)\right]=6 \eta U \frac{d \boldsymbol{h}}{d x}+12 \eta \dot{h_{0}}
$$

which is the Reynolds' equation [7, 21] modified according to the general hydrodynamic lubrication assumption.

According to the stochastically average process of [4, Equation (18) becomes:

$$
\begin{aligned}
\frac{d}{d x}\left[E\left(\boldsymbol{h}^{3}\right) \frac{d}{d x}\left(p-\frac{1}{2} \mu_{0} \bar{\mu} H^{2}\right)\right] & = \\
& =6 \eta U \frac{d}{d x}[E(\boldsymbol{h})]+12 \eta \dot{h_{0}}
\end{aligned}
$$

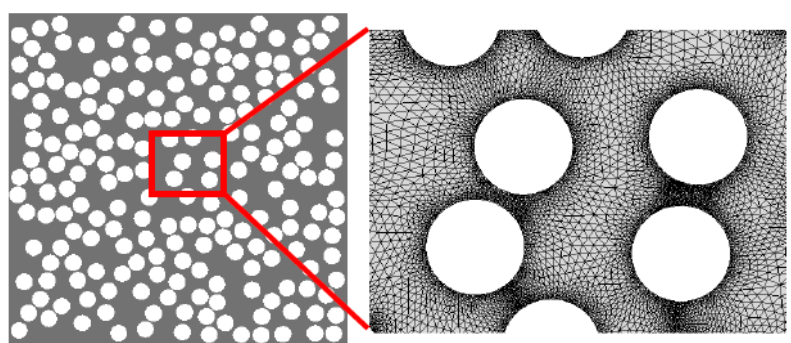

Figure 2. Structure model of porous sheet given by Kozeny-Carman 34].

$$
\begin{gathered}
\frac{d}{d x}\left[g(h, \alpha, \sigma, \varepsilon, \psi) \frac{d}{d x}\left(p-\frac{1}{2} \mu_{0} \bar{\mu} H^{2}\right)\right]= \\
=6 \eta U \frac{d}{d x}\left[g(h, \alpha, \sigma, \varepsilon, \psi)^{1 / 3}\right]+12 \eta \dot{h_{0}}
\end{gathered}
$$

where

$$
\begin{aligned}
g(h, \alpha, \sigma, \varepsilon, \psi)=h^{3} & +3 \alpha h^{2}+3\left(\sigma^{2}+\alpha^{2}\right) h+ \\
+ & 3 \sigma^{2} \alpha+\alpha^{3}+\varepsilon+12 \psi l_{1}
\end{aligned}
$$

\subsection{A GLOBUlar SPHERE MODEL}

Globular particles (a mean particle size Dc) are used to fill a porous material which is given in Fig. 2

In fluid dynamics, the Kozeny-Carman equation [35] plays a major role in calculating the pressure drop when working with a fluid flowing in a packed bed of solids. Although, the equation only remains valid for a laminar flow. This equation makes use of few general experimental trends, which makes it an efficient quality control tool that can be used for both physical as well as digital experimental results. The equation is commonly displayed as permeability versus porosity, pore size and turtuosity.

The pressure gradient is assumed to be linear here. Following the ideas of discussion [36] the use of Kozeny- 
Carman formula becomes:

$$
\psi=\frac{D_{c}^{2} e^{3}}{72(1-e)^{2}} \frac{l}{l^{\prime}}
$$

where $e$ is the porosity and $\frac{l}{l^{\prime}}$ is the length ratio.

The following dimensionless quantities are used,

$$
\begin{gathered}
g(\bar{h}, \bar{\alpha}, \bar{\sigma}, \bar{\varepsilon}, \bar{\psi})=\frac{g(h, \alpha, \sigma, \varepsilon, \psi)}{h_{0}^{3}}, X=\frac{x}{L}, a=\frac{h_{1}}{h_{0}}, \\
\bar{\alpha}=\frac{\alpha}{h_{0}}, \bar{\sigma}=\frac{\sigma}{h_{0}}, \bar{\varepsilon}=\frac{\varepsilon}{h_{0}^{3}}, \bar{p}=\frac{p h_{0}^{2}}{\eta U L}, \\
\mu^{*}=\frac{\mu_{0} \bar{\mu} h_{0}^{2} L k}{\eta U}, \beta_{1}=-\frac{U h_{0}}{2 h_{0} L}, \\
\bar{h}=\frac{h}{h_{0}}=1+(a-1)\left[1-\sin \left(\frac{\pi}{2} X\right)\right], l^{*}=\frac{l}{l^{\prime}}, \\
g(\bar{h}, \bar{\alpha}, \bar{\sigma}, \bar{\varepsilon}, \bar{\psi})^{1 / 3}=\frac{g(h, \alpha, \sigma, \varepsilon, \psi)^{1 / 3}}{h_{0}}, \\
\psi=\frac{D_{c}^{2} e^{3} l}{72(1-e)^{2} l^{\prime}}, \bar{\psi}=\frac{D_{c}^{2} l_{1}}{h_{0}^{3}}
\end{gathered}
$$

The associated boundary conditions are

$$
\bar{p}=0 \text { at } X=0,1
$$

With the aid of equation 22 the pressure distribution in a non-dimensional form comes out to be

$$
\begin{aligned}
\bar{p} & =\frac{1}{2} \mu^{*} X(1-X)+6 \int_{0}^{X}\left[\frac{g(\bar{h}, \bar{\alpha}, \bar{\sigma}, \bar{\varepsilon}, \bar{\psi})^{1 / 3}-\ldots}{g(\bar{h}, \bar{\alpha}, \bar{\sigma}, \bar{\varepsilon}, \bar{\psi})}\right. \\
& \left.\frac{\cdots-g(1, \bar{\alpha}, \bar{\sigma}, \bar{\varepsilon}, \bar{\psi})^{1 / 3}+\beta_{1}^{-1}(1-X)}{g(\bar{h}, \bar{\alpha}, \bar{\sigma}, \bar{\varepsilon}, \bar{\psi})}\right] d X \quad(23)
\end{aligned}
$$

where

$$
\begin{aligned}
g(\bar{h}, \bar{\alpha}, \bar{\sigma}, \bar{\varepsilon}, \bar{\psi}) & =\bar{h}^{3}+3 \bar{\alpha} \bar{h}^{2}+3\left(\bar{\sigma}^{2}+\bar{\alpha}^{2}\right) \bar{h}+ \\
& +3 \bar{\sigma}^{2} \bar{\alpha}+\bar{\alpha}^{3}+\bar{\varepsilon}+\frac{\bar{\psi} e^{3} l^{*}}{6(1-e)^{3}}
\end{aligned}
$$

The load bearing capacity in dimensionless form is obtained

$$
\begin{gathered}
\bar{W}=\frac{h_{0}^{2}}{\eta U L^{2} B} W \\
\bar{W}=\frac{\mu^{*}}{12}+6 \int_{0}^{1}\left[\frac{g(\bar{h}, \bar{\alpha}, \bar{\sigma}, \bar{\varepsilon}, \bar{\psi})^{1 / 3}-\ldots}{g(\bar{h}, \bar{\alpha}, \bar{\sigma}, \bar{\varepsilon}, \bar{\psi})}\right. \\
\left.\frac{\cdots-g(1, \bar{\alpha}, \bar{\sigma}, \bar{\varepsilon}, \bar{\psi})^{1 / 3}+\beta_{1}^{-1}(1-X)}{g(\bar{h}, \bar{\alpha}, \bar{\sigma}, \bar{\varepsilon}, \bar{\psi})}\right](1-X) d X
\end{gathered}
$$

where the load bearing capacity is calculated using

$$
W=\int_{0}^{L} p B d X
$$

\section{Results AND Discussion}

The results calculated for the dimensionless loadcarrying capacity $\bar{W}$ given by equation 26 are found using Simpson's one-third rule with a step size of 0.2 for the Kozeny-Carman model. It proves that the load bearing capacity increases by:

$$
\frac{\mu^{*}}{12}
$$

Equation (26) suggests that even in the absence of a flow, a bearing system can handle a given amount of load for the Kozeny-Carman model. By keeping the roughness zero, the study reduces to the impact of an assorted porous structure on the NeuringerRosensweig model based ferrofluid squeeze film for a slider bearing [7]. Considering the magnetization parameter as a zero, it reduces to the study of [37] in the absence of porosity.

Equation (26) clearly suggests that the expression for $\bar{W}$ is linear with respect to the magnetization parameter $\mu^{*}$. Thus, when the Kozeny-Carman model is applicable, by increasing magnetization, the load bearing capacity can also be increased (Fig. 3). Figures 3 10 display a graphical representation of the Kozeny-Carman model results. They suggest that:

(1.) According to Fig. 4 it is evident that a standard deviation has a relatively lower impact when compared to porosity.

(2.) As the positive variance increases, the load carrying capacity decreases. A decrease in the negative variance leads to an increase in the load carrying capacity (Fig. 5). As suggested by Fig. 6, the impact of skewness on the load carrying capacity is similar to variance.

(3.) Effect of $\bar{\psi}$ on $\bar{W}$ with respect to $e$ and $l^{*}$ is seen to be adversely from Fig. 7

(4.) Figure 8 demonstrates the impact of porosity on the distribution of load carrying capacity. It suggests that porosity considerably reduces the load bearing capacity. In case of a measure of symmetry, this scenario is further exaggerated.

(5.) Figure 9 displays the impact of the ratio $l^{*}$ on the load bearing capacity. It is evident that, with an increase in $l^{*}$, the load bearing capacity decreases. The rate of it is further increased with an increase in porosity parameter $e$.

If we look on the results presented in Fig. 10a and correlate them with the results from Fig. 10, we can firmly conclude that the Kozeny-Carman model is highly activated in reference to the conventional porosity case.

\section{VALidATION}

Undoubtedly, Tables 1 1 5 underline that an enhancement in the load bearing capacity by almost $5 \%$ is registered here. 


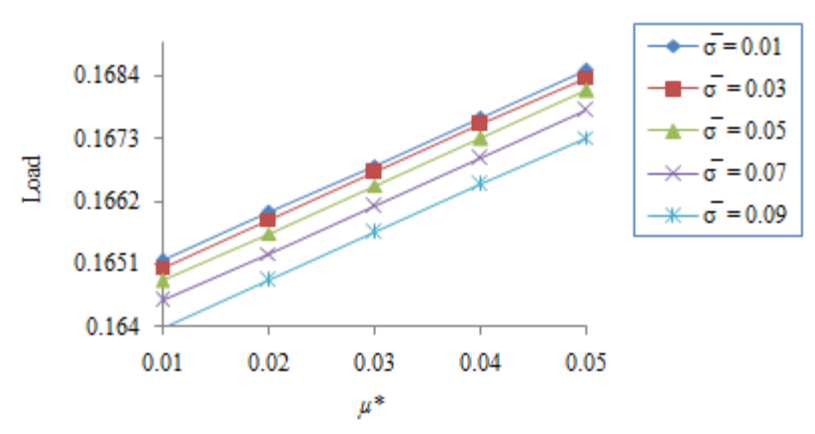

(A).

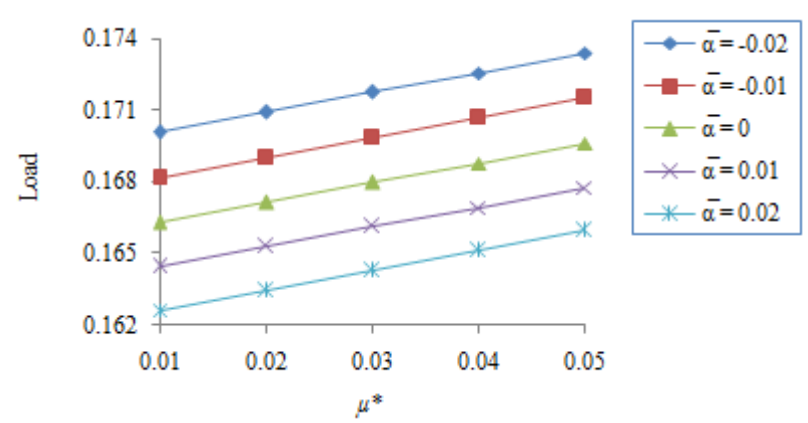

(B).

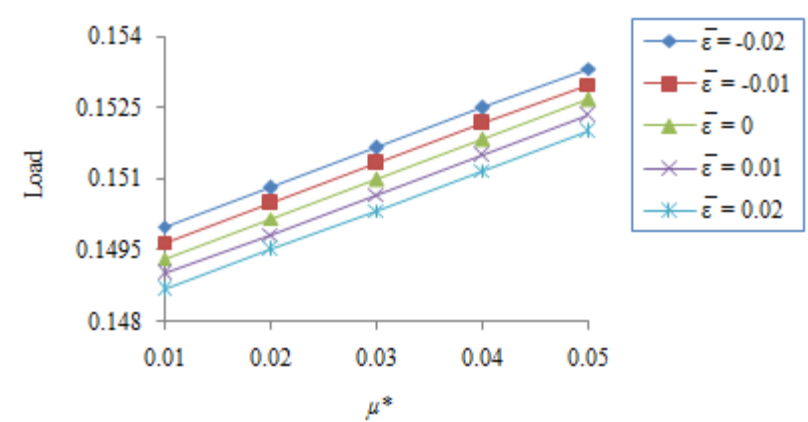

(C).

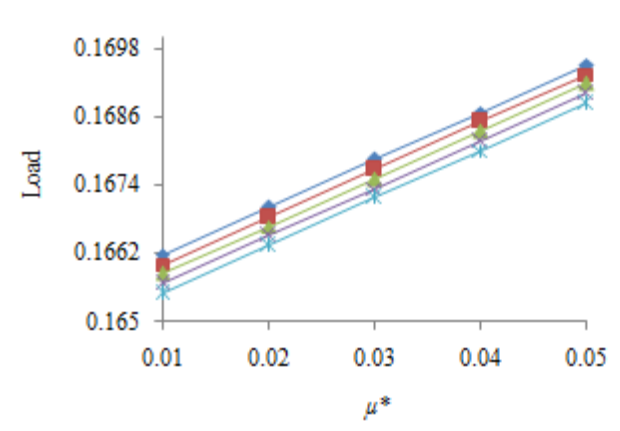

(D).

Figure 3. Profile of load bearing capacity with regards to $\mu^{*}$.

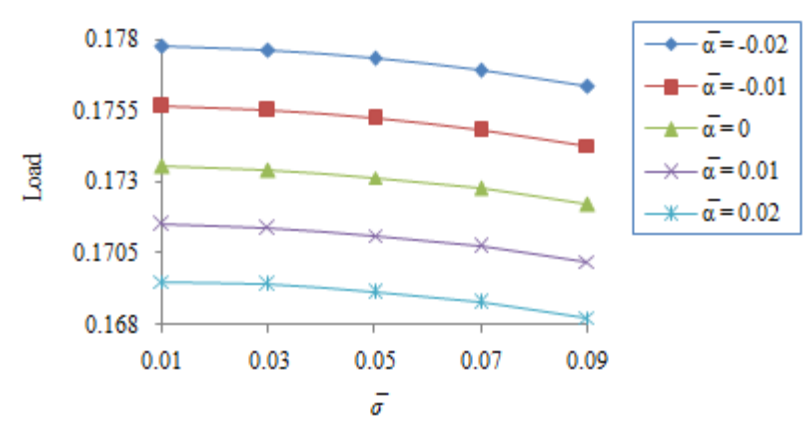

(A).

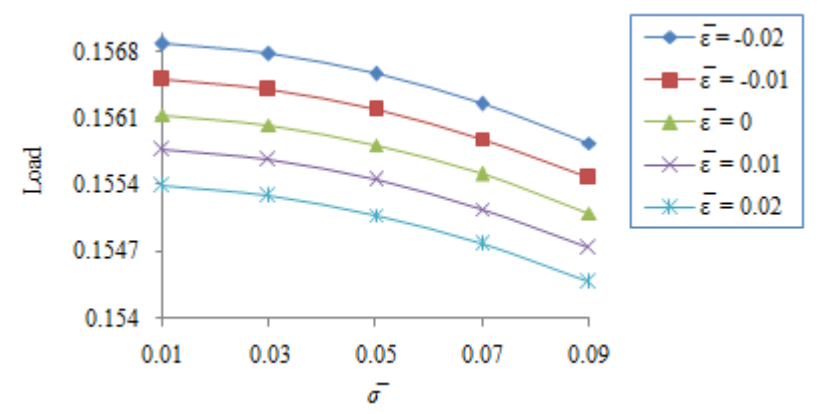

(B).
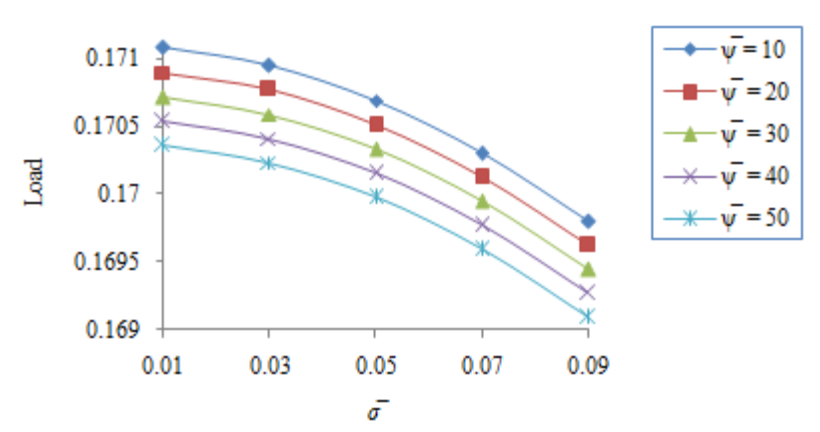

(C).

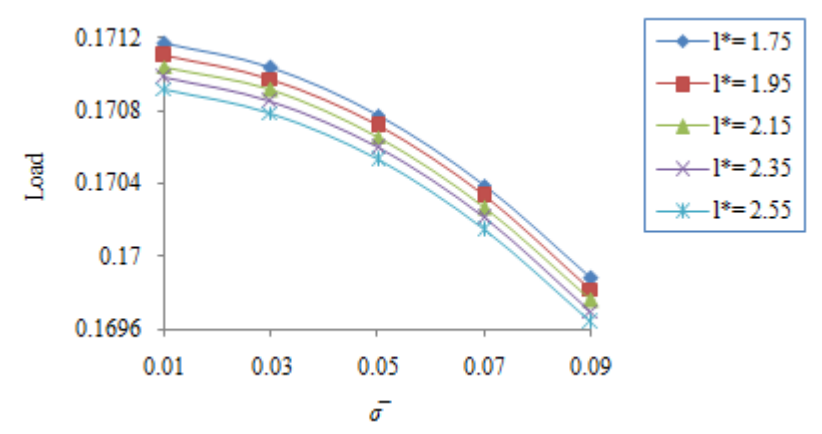

(D).

Figure 4. Profile of load bearing capacity with regards to $\bar{\sigma}$. 


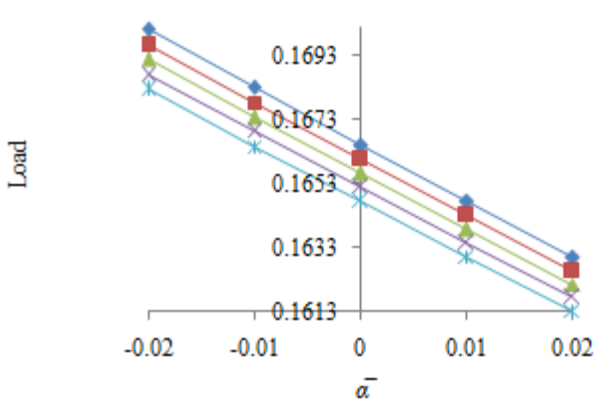

(A).

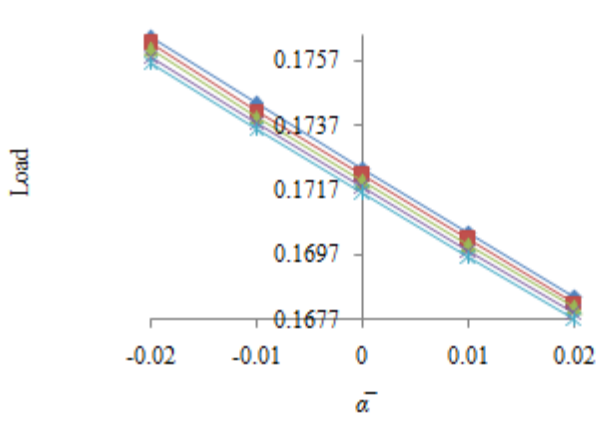

(B).

Figure 5. Profile of load bearing capacity with regards to $\bar{\alpha}$.
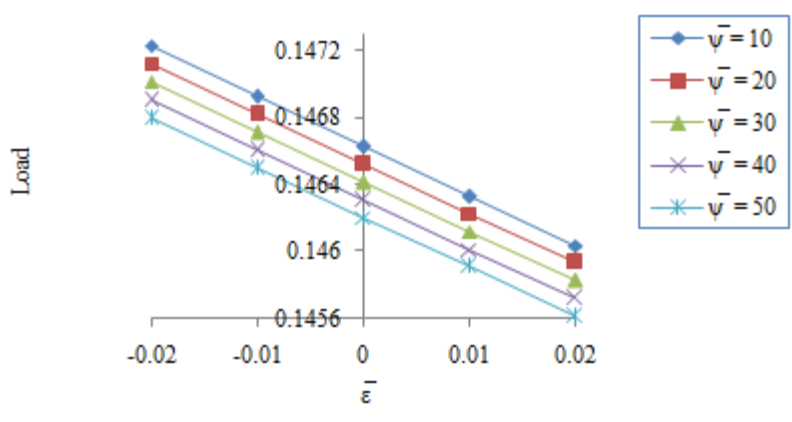

Figure 6. Profile of load bearing capacity with regards to $\bar{\varepsilon}$.

\begin{tabular}{|c|c|c|}
\hline \multirow[t]{2}{*}{$\mu^{*}$} & \multicolumn{2}{|c|}{$\begin{array}{c}\text { Load bearing capacity } \\
\quad \text { calculated for } \\
(\bar{\alpha}=0.01, \bar{\sigma}=0.01, \bar{\varepsilon}=0.05 \\
\bar{\psi}=30,1 / \beta_{1}=0.01, l^{*}=1.75 \\
\left.e=0.15, \psi^{*}=0.02\right)\end{array}$} \\
\hline & $\begin{array}{l}\text { Result for } \\
\text { assorted } \\
\text { porosity }\end{array}$ & $\begin{array}{l}\text { Result for } \\
\text { conventional } \\
\text { porosity }\end{array}$ \\
\hline 0.01 & 0.1651655 & 0.1567618 \\
\hline 0.02 & 0.1659988 & 0.1575952 \\
\hline 0.03 & 0.1668321 & 0.1584285 \\
\hline 0.04 & 0.1676655 & 0.1592618 \\
\hline 0.05 & 0.1684988 & 0.1600952 \\
\hline
\end{tabular}

TABLE 1. Comparison of $\bar{W}$ calculated for $\mu^{*}$.

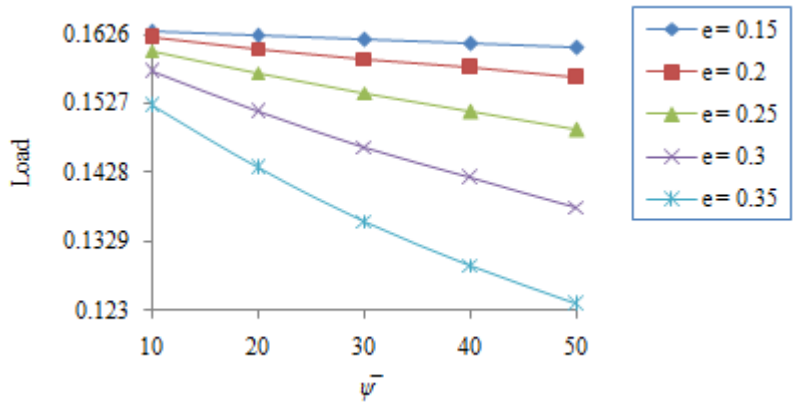

(A).

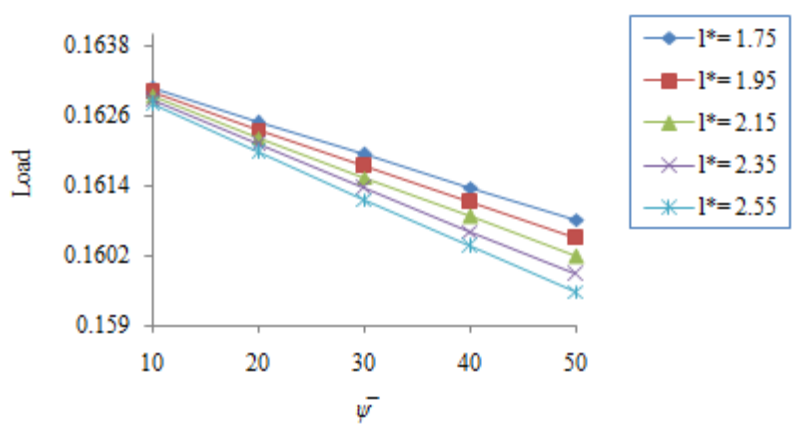

(B).

Figure 7 . Profile of load bearing capacity with regards to $\bar{\psi}$.

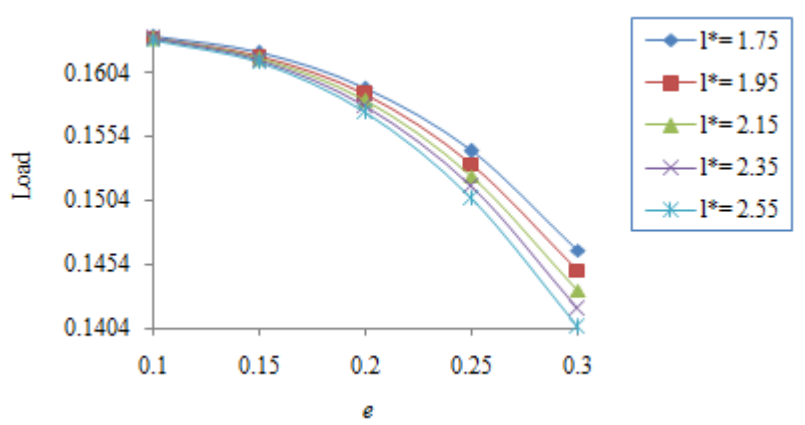

Figure 8. Profile of load bearing capacity with regards to $e$.

\begin{tabular}{ccc}
\hline & \multicolumn{2}{c}{$\begin{array}{c}\text { Load bearing capacity } \\
\text { calculated for }\end{array}$} \\
& \multicolumn{2}{c}{$\left(\mu^{*}=0.02, \bar{\sigma}=0.01, \bar{\varepsilon}=0.05\right.}$, \\
& $\bar{\psi}=30,1 / \beta_{1}=0.01, l^{*}=1.75$, \\
& $\left.e=0.15, \psi^{*}=0.02\right)$ \\
\cline { 2 - 3 } & Result for & Result for \\
& assorted & conventional \\
& porosity & porosity \\
\hline-0.02 & 0.1716939 & 0.1623983 \\
-0.01 & 0.1697629 & 0.1607764 \\
0 & 0.1678648 & 0.1591755 \\
0.01 & 0.1659988 & 0.1575952 \\
0.02 & 0.1641643 & 0.1560354 \\
\hline
\end{tabular}

TABLE 2. Comparison of $\bar{W}$ calculated for $\bar{\alpha}$. 

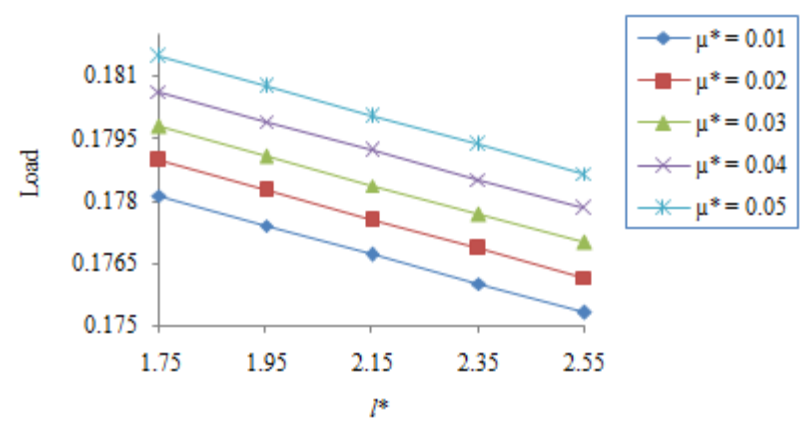

(A).

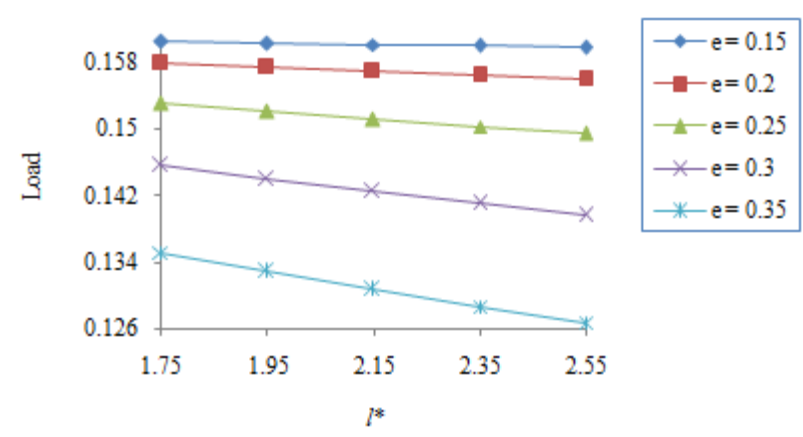

(B).

FiguRE 9. Profile of load bearing capacity with regards to $l^{*}$.

\begin{tabular}{ccc}
\hline & \multicolumn{2}{c}{$\begin{array}{c}\text { Load bearing capacity } \\
\text { calculated for }\end{array}$} \\
$\bar{\sigma}$ & $\begin{array}{c}\left(\mu^{*}=0.02, \bar{\alpha}=0.01, \bar{\varepsilon}=0.05,\right. \\
\bar{\psi}=30,1 / \beta_{1}=0.01, l^{*}=1.75, \\
\end{array}$ & $\left.e=0.15, \psi^{*}=0.02\right)$ \\
\cline { 2 - 3 } & Result for & Result for \\
& assorted & conventional \\
& porosity & porosity \\
\hline 0.01 & 0.1659988 & 0.1575952 \\
0.03 & 0.1658797 & 0.1574952 \\
0.05 & 0.1656424 & 0.1572959 \\
0.07 & 0.1652885 & 0.1569985 \\
0.09 & 0.1648207 & 0.1566048 \\
\hline
\end{tabular}

TABLE 3. Comparison of $\bar{W}$ calculated for $\bar{\sigma}$.

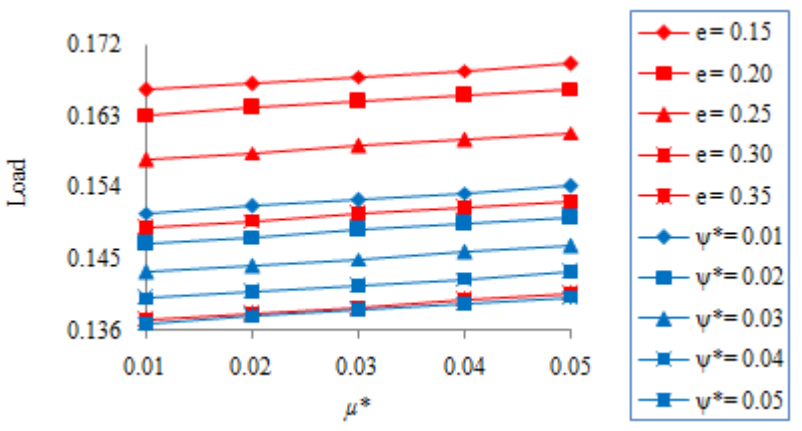

(A).

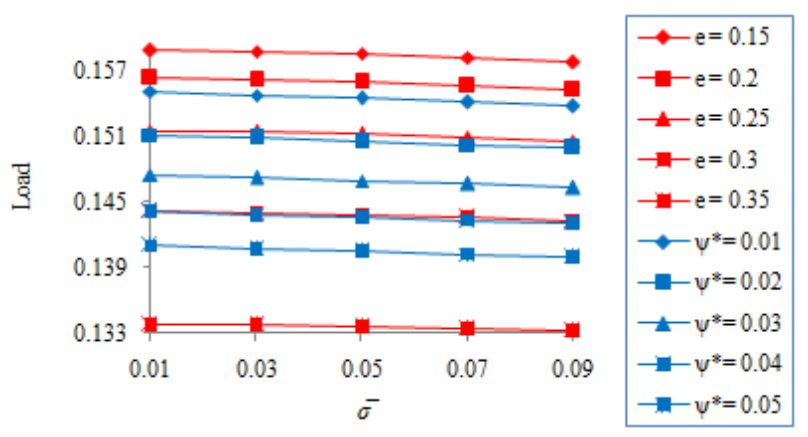

(B).

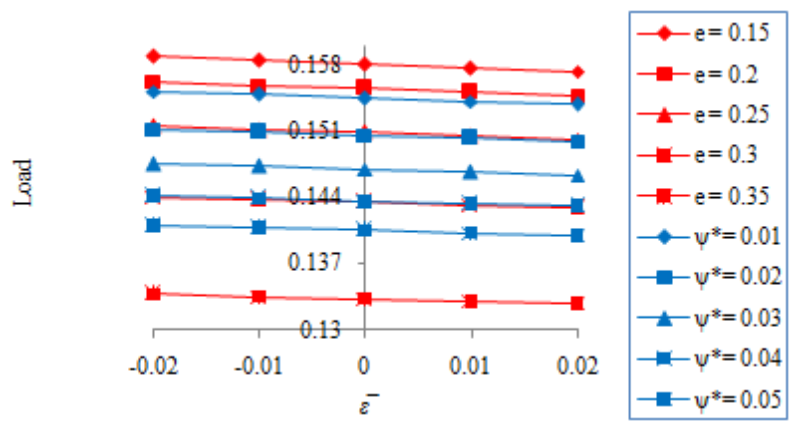

(C).

FIgURE 10. Profile of load bearing capacity with regards to $\mu^{*}, \bar{\sigma}$ and $\bar{\epsilon}$ for the comparison of $e$ and $\psi^{*}$.

\begin{tabular}{|c|c|c|}
\hline \multirow[t]{2}{*}{$\bar{\varepsilon}$} & \multicolumn{2}{|c|}{$\begin{array}{c}\text { Load bearing capacity } \\
\quad \text { calculated for } \\
\left(\mu^{*}=0.02, \bar{\alpha}=0.01, \bar{\sigma}=0.03\right. \\
\bar{\psi}=30,1 / \beta_{1}=0.01, l^{*}=1.75 \\
\left.\quad e=0.15, \psi^{*}=0.02\right)\end{array}$} \\
\hline & $\begin{array}{l}\text { Result for } \\
\text { assorted } \\
\text { porosity }\end{array}$ & $\begin{array}{c}\text { Result for } \\
\text { conventional } \\
\text { porosity }\end{array}$ \\
\hline-0.02 & 0.1692074 & 0.1602794 \\
\hline-0.01 & 0.168718 & 0.1598716 \\
\hline 0 & 0.1682335 & 0.1594672 \\
\hline 0.01 & 0.1677536 & 0.1590663 \\
\hline 0.02 & 0.1672784 & 0.1586686 \\
\hline
\end{tabular}

TABLE 4. Comparison of $\bar{W}$ calculated for $\bar{\varepsilon}$. 


\begin{tabular}{ccc}
\hline & \multicolumn{2}{c}{$\begin{array}{c}\text { Load bearing capacity } \\
\text { calculated for }\end{array}$} \\
& \multicolumn{2}{c}{$\left(\mu^{*}=0.02, \bar{\alpha}=0.01, \bar{\sigma}=0.01\right.}$, \\
& $\begin{array}{c}\bar{\psi}=30, \bar{\varepsilon}=-0.01,1 / \beta_{1}=0.01, \\
\end{array}$ & \multicolumn{2}{c}{$\left.l^{*}=0.08, \psi^{*}=0.02\right)$} \\
\cline { 2 - 3 } & Result for & Result for \\
& assorted & conventional \\
& porosity & porosity \\
\hline 0.1 & 0.1706303 & 0.1599767 \\
0.15 & 0.1699394 & 0.1599767 \\
0.2 & 0.1684007 & 0.1599767 \\
0.25 & 0.1655293 & 0.1599767 \\
0.3 & 0.1607807 & 0.1599767 \\
\hline
\end{tabular}

TABLE 5. Comparison of $\bar{W}$ calculated for $e$.

\section{Conclusions}

This paper has studied the effect of ferrofluid lubrication when used with a rough sine film slider bearing with an assorted porous structure on the load carrying capacity. A modified Reynolds' equation used for the sine profile slider bearing lubrication has been derived with the ferrohydrodynamic theory by Neuringer-Rosensweig and equation of continuity for film as well as porous region. The Reynolds' equation has also been used to determine the pressure equation and an expression for dimensionless load-carrying capacity. From the numerical calculations, the following conclusions have been derived:

(1.) By increasing the strength of the external magnetic field, a bearing system's pressure and its load bearing capacity can be increased considerably. Also, unlike conventional lubricants, this type of a system can carry a given amount of load even if there is no flow. Additionally, as suggested by equation (13), when the Neuringer-Rosensweig ferrofluid flow model is applicable, a constant magnetic field does not increase the load bearing capacity.

(2.) Comparing the present paper with [15] makes it evident that the system, in this case, enhances the load carrying capacity threefold at minimum. Also, when a sine film profile is used to design the slider bearing, it enhances the bearing capacity, as can be seen when compared with an inclined slider bearing.

Lastly, the article determines that, when KozenyCarman's model is appropriate, the surface roughness must be studied properly in order to design a more efficient bearing system.

\footnotetext{
LIST OF SYMBOLS

a inlet-outlet ratio

$B$ breath of the bearing

$g$ function of different parameters

$\boldsymbol{h}$ film thickness [mm]

$h$ mean film thickness [mm]
}

$h_{s}$ deviation from mean level

$h_{1}$ maximum film thickness

$h_{0}$ minimum film thickness

$\bar{h}$ non dimensional film thickness

$\bar{H}$ external magnetic field

$\dot{h_{0}}$ squeeze velocity in z-direction

$H_{0}$ thickness of porous facing

$L \quad$ length of the bearing

$\bar{p}$ non-dimensional film pressure

$w_{0}$ values of $w$ at $z=0$

$w_{h}$ values of $w$ at $z=h$

$W$ load capacity [N]

$\bar{W}$ non-dimensional load capacity

$\alpha$ variance $[\mathrm{mm}]$

$\bar{\alpha}$ non-dimensional variance

$\beta_{1} \quad$ squeeze parameter

$\varepsilon$ skewness $\left[\mathrm{mm}^{3}\right]$

$\bar{\varepsilon} \quad$ skewness in dimensionless form

$\mu_{0} \quad$ magnetic characteristic

$\bar{\mu}$ magnetic susceptibility of particles

$\mu^{*}$ dimensionless magnetization parameter

$\sigma$ standard deviation $[\mathrm{mm}]$

$\bar{\sigma}$ dimensionless standard deviation

$\psi$ permeability of porous region

$\psi^{*}$ dimensionless conventional porosity

\section{ACKNOWLEDGEMENTS}

The authors would like to thank the reviewers for their comments and suggestions, which resulted in an improvement of the materials presented in the paper.

\section{REFERENCES}

[1] P. Andharia, J. L. Gupta, G. Deheri. Effect of surface roughness on hydrodynamic lubrication of slider bearings. Tribology Transaction 44(2):291-297, 2001. DOI:10.1080/10402000108982461

[2] N. Naduvinamani, T. Biradar. Effects of surface roughness on porous inclined slider bearings lubricated with micropolar fluids. Journal of Marine Science and Technology 15(4):278-286, 2007.

[3] N. Naduvinamani, S. Apparao, H. A. Gundayya, S. N. Biradar. Effect of pressure dependent viscosity on couple stress squeeze film lubrication between rough parallel plates. Tribology Online 10(1):76-83, 2015. DOI:10.2474/trol.10.76

[4] H. Christensen, K. C. Tønder. Tribology of rough surfaces: stochastic models of hydrodynamic lubrication. Sintef report 10/69, SINTEF, 1969a.

[5] H. Christensen, K. C. Tønder. Tribology of rough surfaces: parametric study and comparison of lubrication model. Sintef report 22/69, SINTEF, 1969b.

[6] H. Christensen, K. C. Tønder. The hydrodynamic lubrication of rough bearing surfaces of finite width. In ASME-ASLE Lubrication Conference, pp. 12-15. Cincinnati, 1970.

[7] M. V. Bhat. Lubrication with a Magnetic fluid. Team Spirit Pvt. Ltd, India, 2003. 
[8] B. J. Hamrock. Fundamentals of fluid film lubrication. McGraw-Hill, New York, 1994.

[9] J. L. Neuringer, R. E. Rosensweig. Magnetic fluids. Physics of Fluids 7(12):1927-1937, 1964. DOI:10.1063/1.1711103

[10] N. Patel, D. Vakharia, G. Deheri. Hydrodynamic journal bearing lubricated with a ferrofluid. Industrial Lubrication and Tribology 69(5):754-760, 2017. DOI:10.1108/ILT-08-2016-0179

[11] Y. D. Vashi, R. M. Patel, G. Deheri. Ferrofluid based squeeze film lubrication between rough stepped plates with couple stress effect. Journal of Applied Fluid Mechanics 11(3):597-612, 2018. DOI:10.29252/jafm.11.03.27854

[12] R. Shah, M. V. Bhat. Lubrication of a porous exponential slider bearing by ferrofluid with slip velocity. Turkish Journal of Engineering and Environmental Sciences 27:183-187, 2003.

[13] R. Shah, M. V. Bhat. Porous secant shaped slider bearing with slip velocity lubricated by ferrofluid. Industrial Lubrication and Tribology 55(3):113-115, 2003. DOI:10.1108/00368790310470930.

[14] N. B. Naduvinamani, S. Apparao. On the performance of rough inclined stepped composite bearings with micropolar fluid. Journal of Marine Science and Technology 18(2):233-242, 2010.

[15] N. D. Patel, G. Deheri. A ferrofluid lubrication of a rough, porous inclined slider bearing with slip velocity. Journal of Mechanical Engineering and Technology 4(1):15-44, 2012.

[16] P. Ram, P. Verma. Ferrofluid lubrication in porous inclined slider bearing. Indian Journal of Pure and Applied Mathematics 30(12):1273-1281, 1999.

[17] U. P. Singh. On the performance of pivoted curved slider bearings: Rabinowitsch fluid model. In Proceedings of National Tribology Conference. IIT Roorkee, India, 2011.

[18] J. Patel, G. Deheri. Performance of a ferrofluid based rough parallel plate slider bearing: A comparison of three magnetic fluid flow models. Advances in Tribology 2016:1-9, 2016. DOI:10.1155/2016/8197160.

[19] S. Snehal, G. Deheri. Effect of slip velocity on magnetic fluid lubrication of rough porous Rayleigh step bearing. Journal of mechanical engineering and sciences 4:532-547, 2013. DOI:10.15282/jmes.4.2013.17.0050

[20] N. D. Patel, G. Deheri. Hydromagnetic lubrication of a rough porous parabolic slider bearing with slip velocity. Journal of Applied Mechanical Engineering 3(3):1-8, 2014. DOI:10.4172/2168-9873.1000143

[21] S. Patel, G. Deheri, J. Patel. Ferrofluid lubrication of a rough porous hyperbolic slider bearing with slip velocity. Tribology in Industry 36(3):259-268, 2014.

[22] J. R. Lin. Dynamic stiffness and damping characteristics of a sine film thrust bearing. In Proceeding of International Conference on Advanced Manufacture Technology and Industrial Application. China, 2016. DOI:10.12783/dtetr/amita2016/3580.

[23] G. Deheri, J. Patel, N. Patel. Shliomis model based ferrofluid lubrication of a rough porous convex pad slider bearing. Tribology in Industry 38(1):57-65, 2016.
[24] J. Patel, G. Deheri. A study of thin film lubrication at nanoscale for a ferrofluid based infinitely long rough porous slider bearing. Facta Universitatis Series: Mechanical Engineering 14(1):89-99, 2016. DOI:10.22190/FUME1601089P.

[25] V. T. Morgan, A. Cameron. Mechanism of lubrication in porous metal bearings. In Proceedings of Conference on Lubrication and Wear. Institution of Mechanical Engineers, London, 1957.

[26] J. Patel, G. Deheri. A comparison of porous structures on the performance of a magnetic fluid based rough short bearing. Tribology in Industry 35(3):177-189, 2013.

[27] J. Patel, G. Deheri. Performance of a magnetic fluid based double layered rough porous slider bearing considering the combined porous structures. Acta Technica Corviniensis - Bulletin of Engineering 7(4):115-125, 2014.

[28] J. Patel, G. Deheri. Shliomis model-based magnetic squeeze film in rotating rough curved circular plates: A comparison of two different porous structures. International Journal of Computational Materials Science and Surface Engineering 6(1):29-49, 2014. DOI:10.1504/IJCMSSE.2014.063760.

[29] R. Shah, D. B. Patel. Squeeze film based on ferrofluid in curved porous circular plates with various porous structure. Applied Mathematics 2(4):121-123, 2012. DOI:10.5923/j.am.20120204.04

[30] B. Prajapati. On Certain Theoretical Studies in Hydrodynamic and Electro-magneto hydrodynamic Lubrication. Ph.D. thesis, S.P. University, Vallabh Vidyanagar, 1995.

[31] M. Barik, S. Mishra, G. C. Dash. Effect of sinusoidal magnetic field on a rough porous hyperbolic slider bearing with ferrofluid lubrication and slip velocity. Tribology - Materials, Surfaces $\&$ Interfaces 10(3):131137, 2016. DOI:10.1080/17515831.2016.1235843.

[32] S. Mishra, M. Barik, G. C. Dash. An analysis of hydrodynamic ferrofluid lubrication of an inclined rough slider bearing. Tribology - Materials, Surfaces $\mathcal{G}$ Interfaces 12(01):17-26, 2018. DOI:10.1080/17515831.2017.1418280.

[33] P. Verma. Magnetic fluid-based squeeze film. International Journal of Engineering Science 24(3):395401, 1986. DOI:10.1016/0020-7225(86)90095-9.

[34] K. Yazdchi, S. Srivastava, S. Luding. On the validity of the Carman-Kozeny equation in random fibrous media. In II International Conference on Particle-based Methods-Fundamentals and Applications, PARTICLES, pp. 1-10. Barcelona, 2011.

[35] P. C. Carman. Fluid flow through granular beds. Transactions of the Institute of Chemical Engineering 15:150-166, 1937.

[36] J. Liu. Analysis of a porous elastic sheet damper with a magnetic fluid. Journal of Tribology 131(2), 2009. DOI:10.1115/1.3075870.

[37] S. K. Basu, S. N. Sengupta, B. B. Ahuja. Fundamentals of Tribology. PHI Private Limited, New-Delhi, India, 2009. 